\title{
Hubungan Keyakinan dan Noticing dari Calon Guru Sekolah Dasar Mengenai Asesmen Matematika
}

\author{
Kimura Patar Tamba \\ Pendidikan Matematika, Universitas Pelita Harapan \\ Jalan M. H. Thamrin Boulevard 1100 Lippo Village, Tangerang, Banten, Indonesia \\ kimura.tamba@uph.edu
}

Artikel diterima: 05-04-2021, direvisi: 27-09-2021, diterbitkan: 30-09-2021

\begin{abstract}
Abstrak
Penelitian ini dilatarbelakangi oleh pandangan bahwa keyakinan mengenai asesmen mempengaruhi praktek asesmen di dalam kelas. Sementara itu, noticing adalah komponen penting dalam pengembangan kemampuan calon guru untuk memahami praktek asesmen. Tujuan penelitian ini adalah menyelidiki dan mendeskripsikan hubungan antara keyakinan dengan kemampuan noticing dari calon guru sekolah dasar mengenai asesmen matematika. Penelitian ini adalah penelitian kuantitatif korelasional terhadap 68 calon guru sekolah dasar. Data keyakinan mengenai asesmen matematika dikumpulkan dengan menggunakan kuisioner. Sementara data noticing asesmen dikumpulkan dengan video task analysis. Data dianalisis dengan menggunakan statistik deskriptif dan inferensial.. Hasil penelitian menunjukkan tidak terdapat korelasi signifikan antara keyakinan mengenai asesmen dan noticing asesmen. Hasil penelitian juga menunjukkan karateristik noticing cenderung fokus pada aspek "mengajukan pertanyaan" dan tidak komprehensif. Selain itu, calon guru juga cenderung memegang keyakinan produktif namun tidak konsisten.

Kata Kunci: calon guru sekolah dasar, keyakinan mengenai asesmen, noticing.

\section{Relationship between Beliefs and Noticing of Pre-service Elementary Teachers Regarding Mathematics Assessment}

Abstract

This research is motivated by the view that assessment beliefs affect assessment practice in a classroom. Meanwhile, noticing is an important component in the development of assessment practice. The purpose of this study was to investigate and describe the relationship between mathematics assessment beliefs and noticing mathematics assessment. This research is quantitative with a correlational study involving 68 pre-service elementary teachers. Mathematics assessment belief data were collected using a questionnaire. Meanwhile, noticing mathematics assessment data was collected using video task analysis. Data were analyzed using descriptive and inferential statistics The results showed that there was no significant correlation between mathematics assessment belief and noticing mathematics assessment. The results also showed that noticing characteristics tended to focus on the "questioning" aspect and were not comprehensive. Pre-service elementary teachers also tend to hold productive but inconsistent beliefs.

Keywords: pre-service elementary teachers, assessment belief, noticing.
\end{abstract}




\section{Pendahuluan}

Asesmen matematika adalah komponen kunci dalam pembelajaran, di mana proses pengumpulan bukti mengenai pembelajaran matematika dan pengambilan keputusan berdasarkan bukti dilakukan (Baird dkk., 2017; NCTM, 2014; Zhao dkk., 2016). Implikasinya, kualitas pembelajaran matematika sangat ditentukan oleh proses pelaksanaan asesmen. Oleh karena itu, inisiatif reformasi pendidikan matematika juga diarahkan pada reformasi asesmen matematika (Barnes dkk., 2014; Lui \& Bonner, 2016). Komunitas pendidikan matematika juga menyerukan adanya reformasi pada asesmen matematika (NCTM, 2014).

Reformasi asesmen matematika yang dikemukakan mengarah pada penyediaan informasi secara berkelanjutan dan intensional untuk mendukung proses belajar mengajar (Barnes dkk., 2014; Lui \& Bonner, 2016; NCTM, 2014). Perubahan ini berarti menjauhi asesmen secara tradisional. Asesmen matematika secara tradisional cenderung menekankan pada evaluasi prestasi (hasil belajar) siswa, bahkan menentukan peringkat siswa, guru dan sekolah (NCTM, 2014). Praktek asesmen (umum maupuan dalam konteks pembelajaran matematika) yang terjadi di sekolah masih berorientasi pada evaluasi atau akuntabilitas (Brown, 2011; Brown dkk., 2012, 2015; Brown \& Remesal, 2012, 2017). Dengan demikian, reformasi asesmen diarahkan pada perannya dalam mendukung proses belajar mengajar dan manjauhi pandangan tradisional yang menitik beratkan pada evaluasi.

Perubahan arah asesmen matematika ini harus dimulai dari calon guru. Dalam program pendidikan guru, calon guru banyak belajar (termasuk asesmen) dari mengamati praktek pembelajaran diri dan guru lain (misalnya dari guru mentor saat Praktik Pengalaman Lapangan/PPL). Proses mengamati dan menganalisa praktek pembelajaran disebut sebagai noticing. Kemampuan noticing adalah "the ability to attend to and reason about teaching and learning" (Sherin dkk., 2011). Dengan noticing calon guru belajar mengenai asesmen dengan mengamati dan menganalisa praktek pembelajaran yang dilakukan oleh guru (van Es dkk., 2017; Warshauer dkk., 2021; Zambak \& Magiera, 2018). Kemampuan noticing ini memungkinkan calon guru untuk menangkap ide-ide penting dan praktekpraktek baik dalam pelaksanaan asesmen. Untuk itu dalam memperkenalkan praktekpraktek asesmen yang mendukung proses belajar-mengajar (tidak berorientasi evaluasi), kemampuan noticing yang baik penting dimiliki calon guru. Noticing merupakan tindakan mengamati atau mengenali sesuatu dalam konteks pembelajaran. Berbagai literartur dan peneliti mendefinisikan noticing sebagai kemampuan to attend to fitur-fitur pengajaran yang penting, mempertimbangkan apa yang diamati dengan cara yang bermakna dan untuk 
memutuskan bagaimana merespon

(Amador dkk., 2016; Benedict-Chambers \& Aram, 2017; Sherin dkk., 2011). Van Es (2011) mengungkapkan bahwa terdapat dua kategori dalam memahami noticing yaitu apa (fokus) dan bagaimana (kualitas) guru mengamati.

Namun berbagai penelitian mengenai noticing mengungkapkan calon guru sekolah dasar sering tidak mengamati dan menaruh perhatian pada hal-hal penting (Amador dkk., 2016; Benedict-Chambers \& Aram, 2017; Sherin dkk., 2011). Van Es (2011). Misalnya, ketika disuguhkan video pembelajaran dengan maksud untuk belajar mengenai komponen tertentu, calon guru malah mengamati hal lain. Bahkan ketika diberikan kerangka, calon guru tetap sering mangamati hal lain. Hal ini akan menghambat proses belajar calon guru mengenai reformasi asesmen yang diinginkan.

Salah satu faktor yang mempengaruhi noticing calon guru adalah keyakinan. Pedagogik seorang guru dipengaruhi oleh keyakinan mereka mengenai pengajaran, pembelajaran dan asesmen (Doǧan, 2011).

Oleh karena itu, keyakinan akan asesmen dalam matematika sangat penting karena keyakinan ini mempengaruhi praktek asesmen dalam kelas matematika (Martínez-Sierra dkk., 2020; Suurtamm dkk., 2016). Lebih jauh, He dkk. (2011) mengungkapkan bahwa keberhasilan kebijakan pendidikan akan asesmen di tingkat praktis ditentukan oleh keyakinan guru akan asesmen tersebut.

\section{NCTM (2014) mengelompokkan} keyakinan guru akan asesmen menjadi keyakinan produktif dan keyakinan tidak produktif (unproductive belief). Pengelompokan ini berdasarkan peran asesmen dalam pengajaran dan pemelajaran. Keyakinan produktif berarti ketika asesmen dilihat dan digunakan untuk mendukung pengajaran dan pembelajaran yang efektif. Sementara keyakinan tidak produktif berarti asesmen dilihat hanya sebatas mengukur pencapaian dan membatasi siswa pada konten dan praktek matematika yang penting (NCTM, 2014). Contoh keyakinan produktif adalah keyakinan bahwa siswa mampu menilai proses belajar mereka. Di lain pihak, keyakinan tidak produktif melihat asesmen itu harus dilakukan orang luar, tidak bisa oleh siswa sendiri. Oleh karena itu, dalam penelitian ini, terdapat dua domain keyakinan mengenai asesmen yaitu keyakinan produktif dan keyakinan tidak produktif

Penelitian mengenai hubungan keyakinan dengan noticing telah dilakukan oleh Beattie dkk. (2017). Namun dalam penelitian ini masih dalam konteks keyakian matematika dan belajar matematika dengan noticing mengenai berpikir matematika. Dalam konteks keyakinan mengenai asesmen dan noticing asesmen, masih membutuhkan penelitian lebih lanjut. Oleh karena itu, penelitian ini akan fokus pada konteks asesmen, khususnya asesmen. 
Tujuan penelitian ini adalah untuk menyelidiki dan mendeskripsikan hubungan antara keyakinan mengenai asesmen matematika dengan noticing calon guru sekolah dasar mengenai asesmen matematika. Dengan demikian pertanyaan yang menuntun penelitian ini adalah bagaimana hubungan keyakinan mengenai asesmen matematika dengan noticing calon guru sekolah dasar mengenai asesmen matematika?.

\section{Metode}

Penelitian ini adalah penelitian kuantitatif korelasional yang bertujuan menyelidiki hubungan antara keyakinan mengenai assessmen matematika dan noticing asesmen matematika. Subjek penelitian adalah 68 calon guru sekolah dasar (10 laki-laki, 58 perempuan). Subjek penelitian telah menyelesaikan semua perkuliahan yang berhubungan dengan matematika dan asesmen matematika (seperti matematika dasar, matematika sekolah dasar, belajar-mengajar, pedagogik). Penelitian ini dilakukan saat subjek mengikuti perkuliahan microteaching.

Data yang dikumpulkan dalam penelitian ini adalah data keyakinan mengenai asesmen matematika dan data noticing asesmen calon guru sekolah dasar. Data keyakinan mengenai asesmen matematika dikumpulkan menggunakan kuisioner. Kuisioner keyakinan mengenai asesmen matematika terdiri dari dua dimensi yaitu keyakinan produktif dan keyakinan tidak produktif (NCTM, 2014). Pernyataan-pernyataan untuk masingmasing dimensi diperoleh dari NCTM (2014). Kuisioner ini menggunakan skala Likert 1-6 (1 = "sangat tidak setuju" dan 6 = "sangat setuju"). Validasi kuisioner dimulai dengan melakukan CFA (Confirmatory Factor Analysis), hal ini dipilih karena struktur faktor dari instrumen telah diketahui sebelumnya secara teoritik (Brown dkk., 2015). Nilai Kaiser-Meyer-Olkin Measure of Sampling Adequacy adalah 0.57 dan nilai Bartlett's Test of Sphericity sebesar 228,45 $(p=0.00<0.05)$. Artinya prasyarat uji CFA telah dipenuhi. Berdasarkan hasil CFA, terdapat 8 (delapan) pernyataan kuisioner keyakinan mengenai asesmen matematika (Tabel 1). Lima pernyataan untuk dimensi keyakinan tidak produktif dan tiga pernyataan untuk dimensi keyakinan produktif.

Tabel 1

Factor Loadings dari Dua Dimensi

\begin{tabular}{lccc|}
\hline \multicolumn{1}{c}{ Item } & Loading & Mean & Std. Dev \\
\hline I. Keyakinan tidak Produktif & & \\
\hline $\begin{array}{l}\text { P1.Tujuan utama Asesmen (penilaian) adalah pertanggungjawaban } \\
\text { bagi siswa melalui nilai harian atau nilai rapor }\end{array}$ & 0.69 & 4.27 & 1.15 \\
\hline $\begin{array}{l}\text { P2. Harus ada waktu khusus untuk pelaksanaan penilaian (asesmen) } \\
\text { agar tidak menggangu proses pembelajaran }\end{array}$ & 0.76 & 4.03 & 1.32 \\
\hline
\end{tabular}




\begin{tabular}{|c|c|c|c|}
\hline $\begin{array}{l}\text { P3. Penilaian dalam pembelajaran matematika yang paling cocok } \\
\text { adalah soal-soal essai dan pilihan berganda karena handal dan objektif }\end{array}$ & 0.71 & 4.44 & 0.94 \\
\hline $\begin{array}{l}\text { P4. Satu bentuk penilaian (apakah esai atau pilihan berganda) dapat } \\
\text { digunakan untuk membuat keputusan mengenai pemahaman siswa } \\
\text { akan matematika }\end{array}$ & 0.62 & 4.20 & 1.10 \\
\hline P5. Penilaian itu ditujukan kepada siswa & 0.62 & 3.80 & 1.27 \\
\hline \multicolumn{4}{|l|}{ II. Keyakinan Produktif } \\
\hline $\begin{array}{l}\text { P7. Tujuan utama Asesmen adalah untuk menginformasikan dan } \\
\text { meningkatkan proses belajar matematika }\end{array}$ & 0.72 & 5.14 & 0.76 \\
\hline $\begin{array}{l}\text { P9. Pemahaman dan proses matematika dapat diukur melalui berbagai } \\
\text { strategi dan tugas penilaian }\end{array}$ & 0.82 & 5.11 & 0.64 \\
\hline $\begin{array}{l}\text { P10. Berbagai sumber data diperlukan untuk memberikan gambaran } \\
\text { yang akurat tentang kinerja guru dan siswa }\end{array}$ & 0.83 & 5.24 & 0.60 \\
\hline
\end{tabular}

Uji kecocokan model, menunjukkan model pengukuran keyakinan akan asesmen matematika dengan dua faktor telah memenuhi $\left(\mathrm{k}=8 ; \chi^{2}=16,94 ; \mathrm{df}=19\right.$; $\mathrm{p}=0.594 \quad \mathrm{CFI}=1.00 ; \quad \mathrm{RMSEA}=0.00$; AGFI=0.899; GFI=0.946). Setelah CFA, validasi dengan korelasi pearson momentproduct dilakukan. Hasilnya nilai korelasi pearson untuk setiap item pernyataan berada pada rentang 0,236 sampai 0,695 dan signifikan untuk $\alpha=0,05$. Ini menunjukkan kuisioner valid untuk digunakan. Sementara hasil uji reliabilitas dengan Cronbach's Alpha sebesar 0,612 (> $0,5)$ menunjukkan instrumen handal untuk digunakan.

Untuk data noticing asesmen calon guru sekolah dasar dikumpulkan dengan menggunakan video task analysis. Dalam video task analysis, calon guru sekolah dasar diberikan rekaman video dari www.insidemathematics.org. Rekaman video mengenai pelaksanaan asesmen di kelas matematika sekolah dasar. Durasi total video adalah 45 menit yang terbagi menjadi tujuh klip. Analisis video dilakukan calon guru sekolah dasar ditulis dengan bantuan pertanyaan berikut: (a) Apa yang kamu amati mengenai asesmen?; (b) Asesmen seperti apa yang kamu amati dari video tersebut?; (c) Pertanyaanpertanyaan interpretif (Apa artinya bagi Anda, mengapa itu terjadi, bagaimana kejadian itu jika dilihat dari teori belajarmengajar); (d) Berdasarkan informasiinformasi dari pertanyaan (a),(b) dan (c), apa yang akan Anda lakukan jika Anda adalah guru tersebut atau yang akan kamu lakukan ketika kamu menjadi guru?. Hasil noticing ini kemudian diunggah ke Moodle. Validasi data dilakukan dengan koding ulang (re-coding) oleh peneliti lain lalu hasilnya dibandingkan untuk mendapatkan koding yang konsisten.

Analisis data dilakukan dengan menggunakan statistik deskriptif dan statistik inferensial. Analisis dengan statistik deskriptif akan dilakukan pada data keyakinan mengenai asesmen matematika dan noticing asesmen. Statistik deskriptif yang akan digunakan adalah nilai maksimum, minimum, 
frekuensi, rata-rata dan standar deviasi. Untuk data keyakinan mengenai asesmen matematika, analisis ini akan dilakukan untuk masing-masing dimensi. Dimensi yang memiliki nilai mean yang lebih tinggi dibanding dimensi lain menunjukkan bahwa calon guru sekolah dasar cenderung meyakini dimensi tersebut. Oleh karena itu, calon guru sekolah dasar akan dikelompokkan berdasarkan kecenderungan keyakinannya (produktif atau tidak produktif).

Data noticing asesmen calon guru sekolah dasar dimulai dengan melakukan koding pada hasil analisis video. Teknik koding dilakukan secara koding teoritis (theoretical coding). Koding teoritis digunakan karena peneliti akan memakai kerangka teritis dalam menentukan koding (Cohen dkk., 2018). Kerangka teoritis yang digunakan dalam koding ini adalah a research-based FA practice progression (Gotwals dkk., 2015; Lebak, 2018). Kerangka koding ini akan mengkategorikan hasil analisis video mengenai asesmen dikategorikan menjadi: (a) target pembelajaran; (b) pengajuan pertanyaan; (c) pemeriksaan secara intensional; (d) pemberian umpan balik; (e) adaptasi pembelajaran (lihat Tabel 2).

Tabel 2.

Kerangka Noticing mengenai Asesmen Matematika

\begin{tabular}{ll|}
\hline \multicolumn{1}{c}{ Kategori } & \multicolumn{1}{c}{ Deskripsi } \\
\hline Tujuan pembelajaran & - Guru mengkomunikasikan target, capaian atau tujuan pembelajaran \\
& - Tujuan pembelajaran dipahami dengan jelas oleh siswa \\
\hline Pengajuan pertanyaan & - Tujuan pertanyaannya jelas \\
& - Pertanyaan mewakili tingkat kompleksitas yang berbeda \\
& - Tanggapan siswa dan pertanyaan tindak lanjut guru dicatat \\
\hline Pemeriksaan secara & - Hal yang dilakukan untuk mencek pemahaman siswa: misalnya, dengan \\
intensional & hand signals, menulis di papan tulis, mengamati \\
\hline Pemberian Umpan balik & - Guru memberikan umpan balik secara tepat waktu dan spesifik \\
\hline Adaptasi Pembelajaran & - Memberikan scaffolding \\
& - Mengklarifikasi pemahaman \\
& - Memberikan contoh (modeling) \\
& - Mengajarkan ulang konsep \\
& - Membentuk kelompok kecil \\
& - Memberikan tantangan atau memberikan materi lanjut (pengayaan)
\end{tabular}

Setelah proses koding dilakukan, asesmen calon guru sekolah dasar akan statistik deskriptif (frekuensi, mean, nilai dianalisis berdasarkan kategori asesmen. maksimum, nilai minimum dan standar Selain itu, noticing asesmen calon guru deviasi) akan digunakan untuk sekolah dasar juga akan dideskripsikan memberikan deskriptif kuantitatif berdasarkan tingkat komprehensifnya, mengenai fokus noticing asesmen calon yaitu 0 (tidak mengamati satu kategori guru sekolah dasar. Deskripsi noticing 
pun) sampai 5 (mengamati semua kategori).

Analisis statistik inferensial dengan uji korelasi dilakukan untuk memeriksa hubungan antara keyakinan mengenai asesmen matematika dengan noticing asesmen calon guru sekolah dasar. Uji korelasi dilakukan pada 68 pasangan data keyakinan mengenai asesmen dan data noticing asesmen calon guru sekolah dasar. Uji korelasi ini menggunakan statistik Kendall's Tau.

\section{Hasil dan Pembahasan}

\section{A. Keyakinan mengenai Asesmen Matematika}

Analisis deskriptif keyakinan mengenai asesmen matematika dilakukan dengan perhitungan statistik deskriptif untuk masing-masing dimensi keyakinan. Hasil tersebut terlihat pada Tabel 3. Hasil ini menunjukkan rata-rata skor keyakinan produktif $(5,16)$ lebih tinggi dibanding rata-rata skor keyakinan tidak produktif $(4,15)$. Ini artinya bahwa secara keseluruhan calon guru sekolah dasar lebih cenderung memegang keyakinan produktif dibanding keyakinan tidak produktif.

Tabel 3.

Deskripsi Keyakinan mengenai Asesmen

\begin{tabular}{lllll}
\hline \multicolumn{4}{c}{ Matematika } \\
& Min. & Max. & $\begin{array}{c}\text { Rata- } \\
\text { rata }\end{array}$ & Std.Dev. \\
\hline $\begin{array}{l}\text { Keyakinan } \\
\text { Tidak } \\
\text { Produktif }\end{array}$ & 1.40 & 5.60 & 4.15 & 0.79 \\
$\begin{array}{l}\text { Keyakinan } \\
\text { Produktif }\end{array}$ & 3.00 & 6.00 & 5.16 & 0.53 \\
\hline
\end{tabular}

Meskipun demikian, rata-rata skor dari keyakinan produktif lebih tinggi dari 4 menunjukkan bahwa calon guru sekolah dasar juga memegang dengan kuat keyakinan tidak produktif akan asesmen matematika. Artinya, calon guru sekolah dasar memegang kedua keyakinan, meskipun lebih cenderung pada keyakinan produktif.

\section{B. Noticing Asesmen Matematika}

Analisis deskriptif noticing asesmen matematika diawali dengan menghitung frekuensi calon guru sekolah dasar yang mengamati kategori asesmen. Tabel 4 menunjukkan frekuensi calon guru sekolah dasar yang mengamati aspek "pengajuan pertanyaan" lebih tinggi (69\%) dibanding aspek lain. Hal ini menunjukkan dan bermakna bahwa calon guru sekolah dasar cenderung fokus pada aspek "pengajuan pertanyaan" ketika mengamati mengenai asesmen. Aspek penting lain dalam asesmen seperti "pemberian umpan balik", "adaptasi pembelajaran" mendapat sedikit perhatian calon guru sekolah dasar. Hal ini juga bermakna calon guru sekolah dasar melihat aspek yang paling penting dalam asesmen adalah "mengajukan pertanyaan" yaitu pertanyaan, bentuk soal, jawaban siswa.

Tabel 4.

Karateristik Fokus Noticing Pre-Service Teachers

\begin{tabular}{lcc|}
\hline \multicolumn{1}{c}{ Fokus Noticing } & Freq & Persentase \\
\hline Tujuan Pembelajaran & 13 & $18,3 \%$ \\
\hline $\begin{array}{l}\text { Pengajuan } \\
\text { Pertanyaan }\end{array}$ & 49 & $69,0 \%$ \\
\hline $\begin{array}{l}\text { Pemeriksanan secara } \\
\text { Intensional }\end{array}$ & 31 & $43,7 \%$ \\
\hline
\end{tabular}




\begin{tabular}{|c|c|c|c|}
\hline $\begin{array}{l}\text { Pemberian } \\
\text { Balik }\end{array}$ & Umpan & 16 & $22,5 \%$ \\
\hline $\begin{array}{l}\text { Adaptasi } \\
\text { Pembelajarar }\end{array}$ & & 27 & $38,0 \%$ \\
\hline
\end{tabular}

Berikutnya dianalisis tingkat komprehensif noticing asesmen calon guru sekolah dasar. Tabel 5 menunjukkan tidak ada $(0 \%)$ calon guru sekolah dasar yang mengamati semua aspek. Bahkan ada 7 (10\%) calon guru sekolah dasar yang tidak mengamati satu aspek pun mengenai asesmen. Hasil analisis ini bermakna bahwa noticing calon guru sekolah dasar hanya fokus pada aspek tertentu saja. Dengan demikian, noticing calon guru sekolah dasar tidak komprehensif mengamati semua aspek asesmen. Hal ini sesuai juga dengan nilai rata-rata tingkat komprehensif noticing calon guru sebesar 1,94 ( $\min =1, \quad \max =4$, std.dev $=1,08$ ). Artinya secara umum calon guru sekolah dasar masih fokus pada dua aspek dari asesmen.

Tabel 5.

Tingkat Komprehensif Fokus Noticing

\begin{tabular}{|ccr|}
\hline Tingkat Komprehensif & Freq & Persentase \\
\hline Tidak satupun aspek & 7 & $10 \%$ \\
\hline Satu Aspek & 16 & $24 \%$ \\
\hline Dua Aspek & 24 & $35 \%$ \\
\hline Tiga Aspek & 16 & $24 \%$ \\
\hline Empat Aspek & 5 & $7 \%$ \\
\hline Lima Aspek & 0 & $100 \%$ \\
\hline Total & 68 & \\
C. Hubungan & Keyakinan & mengenai \\
Asesmen dan & Noticing & Asesmen \\
Matematika & &
\end{tabular}

Analisis hubungan antara keyakinan mengenai asesmen dan noticing asesmen matematika calon guru sekolah dasar dilakukan pada pasangan rata-rata skor keyakinan mengenai asesmen dan skor tingkat komprehensif noticing asesmen calon guru. Selain itu, analisis hubungan juga dilakukan pada pasangan data dimensi keyakinan produktif dan skor tingkat komprehensif noticing asesmen calon guru sekolah dasar. Begitu juga pada pasangan data dimensi keyakinan tidak produktif dan skor tingkat komprehensif noticing asesmen calon guru sekolah dasar.

Tabel 6.

Nilai Korelasi Keyakinan dan Noticing

\begin{tabular}{lccc|}
\hline $\begin{array}{l}\text { Keyakinan } \\
\text { mengenai } \\
\text { Asesmen }\end{array}$ & \multicolumn{3}{c}{$\begin{array}{c}\text { Tingkat Komprehensif } \\
\text { Noticing }\end{array}$} \\
\hline & $\mathrm{N}$ & $\mathrm{T}_{\mathrm{b}}$ & $\mathrm{Sig}$ \\
\hline Total & 69 & 0,093 & 0,325 \\
\hline $\begin{array}{l}\text { Keyakin } \\
\text { Produktif }\end{array}$ & 69 & 0,042 & 0,677 \\
\hline $\begin{array}{l}\text { Keyakinan } \\
\text { Tidak } \\
\text { Produktif }\end{array}$ & 69 & 0,096 & 0,309 \\
\hline
\end{tabular}

Keterangan:

$\mathrm{T}_{\mathrm{b}}=$ Kendall's Tau 
asesmen matematika dan noticing asesmen matematika. Penelitian ini sesuai dengan penelitian sebelumnya yang menunjukkan tidak adanya korelasi signifikan antara keyakinan dan noticing. Pada penelitian Beattie dkk. (2017) tingkat noticing malah berkorelasi negatif dan tidak signifikan dengan noticing mengenai berpikir matematika (mathematical thinking) calon guru. Hal ini bisa terjadi karena keyakinan calon guru cenderung tidak konsisten (Beswick, 2012; Felbrich dkk., 2012; Tang \& Hsieh, 2014; Yang dkk., 2020).

Temuan lain yang mendukung temuan di atas adalah noticing asesmen dari calon guru sekolah tidak komprehensif dan cenderung hanya fokus pada aspek "mengajukan pertanyaan". Hasil ini sejalan dengan penelitian sebelumnya, yang menunjukkan bahwa calon guru cenderung hanya fokus pada aspek "mengajukan pertanyaan" dalam asesmen (Lebak, 2018). Padahal aspek-aspek seperti "memberikan umpan balik" dan "adaptasi pembelajaran" adalah hal yang esensial dari asesmen (NCTM, 2014). Hasil penelitian di atas juga menunjukkan temuan lain yaitu calon guru sekolah dasar memegang kedua keyakinan produktif dan tidak produktif mengenai asesmen, meskipun lebih cenderung pada keyakinan produktif. Artinya, keyakinan mengenai asesmen matematika calon guru sekolah dasar cenderung tidak konsisten. Penelitian terdahulu mengungkapkan hal ini mungkin terjadi (Beswick, 2012;
Felbrich dkk., 2012; Tang \& Hsieh, 2014; Yang dkk., 2020).

Berdasarkan diskusi di atas, penelitian ini memberikan kontribusi dalam dua hal. Pertama, temuan penelitian ini memberikan kontribusi pada analisis hubungan keyakinan dan noticing dalam konteks asesmen matematika. Ini semakin menguatkan penelitian sebelumnya yang meneliti dalam konteks hubungan keyakinan matematika dan belajar matematika dengan berpikir matematis (mathematical thinking) (Beattie dkk., 2017). Kedua, temuan penelitian ini juga semakin mengkonfirmasi bahwa calon guru cenderung memiliki keyakinan yang tidak konsisten.

\section{Penutup}

Hasil yang telah diuraikan di atas menjawab pertanyaan penelitian yaitu tidak terdapat korelasi signifikan antara keyakinan mengenai asesmen dan noticing asesmen calon guru sekolah dasar. Hasil penelitian di atas juga menunjukkan karateristik keyakinan mengenai asesmen yaitu sekolah dasar memegang kedua keyakinan produktif dan tidak produktif mengenai asesmen, meskipun lebih cenderung pada keyakinan produktif. Selain itu, hasil penelitian juga menunjukkan karateristik noticing yaitu calon guru cenderung hanya fokus pada aspek "mengajukan pertanyaan".

Hasil penelitian ini memberikan implikasi pada praktik pembelajaran yaitu pentingnya penguatan pada keyakinan dan 
praktik asesmen matematika. Guru penting secara terus-menerus didorong untuk semakin kuat dalam memegang dan mempraktikkan keyakinan produktif mengenai asesmen matematika.

Berdasarkan hasil penelitian di atas, penelitian selanjutnya perlu dilakukan untuk menganalisis lebih jauh faktor-faktor dibalik tidak signifikannya korelasi keyakinan mengenai asesmen dan noticing asesmen calon guru sekolah dasar. Hal ini penting karena keyakinan mengenai asesmen dan noticing merupakan komponen penting dalam kemampuan guru mengkonstruksi pembelajaran yang bermakna dan efektif.

\section{DAfTAR PUStaka}

Amador, J. M., Carter, I., \& Hudson, R. A. (2016). Analyzing Preservice Mathematics Teachers' Professional Noticing. Action in Teacher Education, 38(4), 371-383.

Baird, J. A., Andrich, D., Hopfenbeck, T. N., \& Stobart, G. (2017). Assessment and learning: fields apart? Assessment in Education: Principles, Policy and Practice, 24(3), 317-350.

Barnes, N., Fives, H., \& Dacey, C. M. (2014). Teachers' beliefs about assessment. In H. Fives \& M. G. Gill (Eds.), International Handbook of Research on Teachers' Beliefs (pp. 1502). New York: Routledge.

Beattie, H. L., Ren, L., Smith, W. M., Heaton, R. M., \& In-service, Á. Á. (2017). Measuring Elementary
Mathematics Teachers' Noticing: Using Child Study as a Vehicle. In E. O. Schack, M. H. Fisher, \& J. A. Wilhelm (Eds.), Teacher Noticing: Bridging and Broadening Perspectives, Contexts, and Frameworks (pp. 321-338). Cham: Springer.

Benedict-Chambers, A., \& Aram, R. (2017). Tools for teacher noticing: Helping preservice teachers notice and analyze student thinking and scientific practice use. Journal of Science Teacher Education, 28(3), 294-318.

Beswick, K. (2012). Teachers' beliefs about school mathematics and mathematicians' mathematics and their relationship to practice. Educational Studies in Mathematics, 79(1), 127-147.

Brown, G. T. L. (2011). Self-regulation of assessment beliefs and attitudes: A review of the students' conceptions of assessment inventory. Educational Psychology, 31(6), 731-748.

Brown, G. T. L., Chaudhry, H., \& Dhamija, R. (2015). The impact of an assessment policy upon teachers' selfreported assessment beliefs and practices: A quasi-experimental study of Indian teachers in private schools. International Journal of Educational Research, 71(1), 50-64.

Brown, G. T. L., Harris, L. R., \& Harnett, J. (2012). Teacher beliefs about feedback within an assessment for learning environment: Endorsement of improved learning over student 
well-being. Teaching and Teacher Education, 28(7), 968-978.

Brown, G. T. L., \& Remesal, A. (2012). Prospective Teachers' Conceptions of Assessment: A Cross-Cultural Comparison. The Spanish Journal of Psychology, 15(1), 75-89.

Brown, G. T. L., \& Remesal, A. (2017). Teachers' conceptions of assessment: Comparing two inventories with Ecuadorian teachers. Studies in Educational Evaluation, 55(June), 6874.

Cohen, L., Manion, L., \& Morrison, K. (2018). Research Methods in Education (8th ed.). New York: Routledge.

Doǧan, M. (2011). Student teachers' views about assessment and evaluation methods in mathematics. Educational Research and Reviews, 6(5), 417-431. Felbrich, A., Kaiser, G., \& Schmotz, C. (2012). The cultural dimension of beliefs: an investigation of future primary teachers' epistemological beliefs concerning the nature of mathematics in 15 countries. ZDM International Journal on Mathematics Education, 44(3), 355-366.

Gotwals, A. W., Philhower, J., Cisterna, D., \& Bennett, S. (2015). Using Video to Examine Formative Assessment Practices as Measures of Expertise for Mathematics and Science Teachers. International Journal of Science and Mathematics Education, 13(2), 405423.
He, Q., Valcke, M., \& Aelterman, A. (2011). Pre-service teachers' beliefs about evaluation. Procedia - Social and Behavioral Sciences, 29, 1296-1304.

Lebak, K. (2018). Analyzing on-line video club discussions focused on formative assessment. Education and Information Technologies, 23(5), 1789-1804.

Lui, A. M., \& Bonner, S. M. (2016). Preservice and inservice teachers' knowledge, beliefs, and instructional planning in primary school mathematics. Teaching and Teacher Education, 56(1), 1-13.

Martínez-Sierra, G., García-García, J., ValleZequeida, M., \& Dolores-Flores, C. (2020). High School Mathematics Teachers' Beliefs About Assessment in Mathematics and the Connections to Their Mathematical Beliefs. International Journal of Science and Mathematics Education, 18(3), 485507.

NCTM. (2014). Principles to Actions: Ensuring Mathematical Success for All. Reston: The National Council of Teachers of Mathematics, Inc.

Sherin, M. G., Jacobs, Vi. R., \& Philipp, R. A. (2011). Situating the study of teacher noticing. In M. G. Sherin, Vi. R. Jacobs, \& R. A. Philipp (Eds.), Mathematics Teacher Noticing Seeing Through Teachers' Eyes (pp. 1-13). New York: Routledge.

Suurtamm, C., Thompson, D. R., Kim, R. Y., Moreno, L. D., Sayac, N., Schukajlow, 
S., Silver, E., Ufer, S., \& Vos, P. (2016). Assessment in Mathematics Education: Large-Scale Assesment and Classroom Assessment. Springer.

Tang, S. J., \& Hsieh, F. J. (2014). The cultural notion of teacher education: Future lower secondary teachers' beliefs on the nature of mathematics, the learning of mathematics and mathematics achievement. In $\mathrm{S}$. Blömeke, F. J. Hsieh, G. Kaiser, \& W. Schmidt (Eds.), The Conceptualisation of Mathematics Competencies in the International Teacher Education Study TEDS-M (pp. 231-253). Cham: Springer.

Van Es, E. A. (2011). A framework for learning to notice students' thinking. In M. G. Sherin, V. R. Jacobs, \& R. A. Philipp (Eds.), Teacher Noticing Seeing Trouugh Teachers' Eyes (pp. 134151). New York: Routledge.

Van Es, E. A., Cashen, M., Barnhart, T., \& Auger, A. (2017). Learning to Notice Mathematics Instruction: Using Video to Develop Preservice Teachers' Vision of Ambitious Pedagogy. Cognition and Instruction, 35(3), 165-187.

Warshauer, H. K., Starkey, C., Herrera, C. A., \& Smith, S. (2021). Developing prospective teachers' noticing and notions of productive struggle with video analysis in a mathematics content course. Journal of Mathematics Teacher Education, 24(1), 89-121.
Yang, X., Kaiser, G., König, J., \& Blömeke, S. (2020). Relationship between pre service mathematics teachers 'knowledge, beliefs and instructional practices in China. ZDM, 52(2), 281294.

Zambak, V. S., \& Magiera, M. T. (2018). Pre-service K-8 teachers' professional noticing and strategy evaluation skills: An exploratory study. Eurasia Journal of Mathematics, Science and Technology Education, 14(11).

Zhao, X., Van den Heuvel-Panhuizen, M., \& Veldhuis, M. (2016). Teachers' use of classroom assessment techniques in primary mathematics education-an explorative study with six Chinese teachers. International Journal of STEM Education, 3(1).

\section{Riwayat Hidup Penulis} Kimura Patar Tamba, M.Pd.

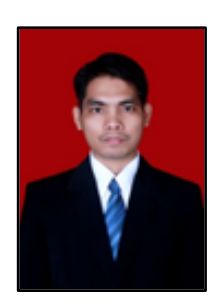

Lahir di Labuhan Batu Utara, 8 Januari 1989. Staf pengajar di Universitas Pelita Harapan. Studi S1 Pendidikan Matematika Universitas Negeri Medan, Medan, lulus tahun 2012; S2 Pendidikan Matematika Universitas Pendidikan Indonesia, Bandung, lulus tahun 2015. 